\title{
Release kinetics of lime essential oil (Citrus aurantifolia) from beads microencapsulated through ion-gel method
}

\author{
Vinh Truong*, Phuong T. Nguyen, Nhung T. C. Pham, \& Phuong T. Nguyen \\ Department of Chemical Engineering, Nong Lam University, Ho Chi Minh City, Vietnam
}

\begin{abstract}
ARTICLE INFO
Research Paper

Received: November 15, 2020

Revised: February 12, 2021

Accepted: February 23, 2021

Keywords

Ca-Alginate

Ion-gel method

Lime oil

Microencapsulation

Release kinetic

${ }^{*}$ Corresponding author

Truong Vinh

Email: tv@hcmuaf.edu.vn
\end{abstract}

\begin{abstract}
Ca-Alginate beads for microencapsulation of lime oil (Citrus aurantifolia) by ion-gel method was manufactured and then soaked in Chitosan solution to obtain Ca-Alginate-Chitosan beads. Increased $\mathrm{CaCl}_{2}$ concentrations reduced lime essential oil release. The alginate concentration (2 to $3 \%)$ and water temperature affected significantly the release of oil $(P<0.05)$. The higher temperatures, the higher the release rate. The oil release at $75^{\circ} \mathrm{C}$ was twice as much as at $45^{\circ} \mathrm{C}$. At $45^{\circ} \mathrm{C}$, the difference in the release rate among the alginate concentrations of $2 \%, 2.5 \%$ and $3 \%$ was clear and statistically significant $(P<0.05)$. However, at $60^{\circ} \mathrm{C}$ and $75^{\circ} \mathrm{C}$, there was no significant difference in release between the alginate concentration of $2.5 \%$ and $3 \%(P>0.05)$. In the storage of beads in $1 \% \mathrm{CaCl}_{2}$ solution at normal temperature, after the first 15 days, Ca-Alginate-Chitosan system released about 3\% slower than Ca-Alginate system, but there was no difference between the two systems after 45 days. This shows that if prolonged for a long time, the ion-gelation of Ca-Alginate prevails over the Alginate-Chitosan cross-link.
\end{abstract}

Cited as: Truong, V., Nguyen, P. T., Pham, N. T. C., \& Nguyen, P. T. (2021). Release kinetics of lime essential oil (Citrus aurantifolia) from beads microencapsulated through ion-gel method. The Journal of Agriculture and Development 20(1), 58-66. 


\title{
Nghiên cứu động học phóng thích của tinh dầu chanh từ hạt vi bọc bằng phương pháp ion-gel
}

\author{
Trương Vĩnh*, Nguyễn Thành Phương, Phạm Thị Cẩm Nhung \& Nguyễn Thanh Phương \\ Bộ Môn Công Nghệ Hóa Học, Trường Đại Học Nông Lâm TP.HCM, TP. Hồ Chí Minh
}

THÔNG TIN BÀI BÁO
Bài báo khoa học
Ngày nhận: 15/11/2020
Ngày chỉnh sửa: 12/02/2021
Ngày chấp nhận: 23/02/2021
Từ khóa
Ca-alginate
Động học phóng thích
Phương pháp ion-gel
Tinh dầu chanh
Vi bọc
*Tác giả liên hệ
Trương Vĩnh
Email: tv@hcmuaf.edu.vn

\section{TÓM TẮT}

Hạt Ca-Alginate vi bọc tinh dầu chanh bằng phương pháp ion-gel được thực hiện và sau đó ngâm trong dịch Chitosan để có hạt Ca-AlginateChitosan. Nồng độ $\mathrm{CaCl}_{2}$ tăng làm giảm sự phóng thích tinh dầu chanh. Nồng độ alginate $(2-3 \%)$ và nhiệt độ nước ngâm ảnh hưởng đến sự phóng thích tinh dầu chanh $(P<0,05)$. Ở nhiệt độ càng cao, tốc độ phóng thích càng lớn. Độ phóng thích tinh dầu ở nhiệt độ $75^{\circ} \mathrm{C}$ cao hơn hai lần ở nhiệt độ $45^{\circ} \mathrm{C}$. Ở nhiệt độ $45^{\circ} \mathrm{C}$, sự khác biệt tốc độ phóng thích giữa 3 nồng độ alginate $2 \% ; 2,5 \%$ và $3 \%$ rõ ràng và có ý nghĩa thống kê $(P<0,05)$. Tuy nhiên, ở nhiệt độ $60^{\circ} \mathrm{C}$ và $75^{\circ} \mathrm{C}$, không có sự khác biệt về độ phóng thích giữa nồng độ alginate $2,5 \%$ và $3 \%(P>0,05)$. Trong quá trình bảo quản hạt vi bọc trong môi trường $\mathrm{CaCl}_{2} 1 \%$ ở nhiệt độ thường, sau thời gian 15 ngày đầu hệ Ca-Alginate-Chitosan phóng thích chậm hơn hệ Ca-Alginate khoảng $3 \%$ nhưng không khác biệt giữa hai hệ sau 45 ngày. Điều này cho thấy nếu kéo dài thời gian lâu thì liên kết Ca-Alginate chiếm ưu thế so với liên kết Alginate-Chitosan.

\section{1. Đặt Vấn Đề}

Công nghệ vi bọc hoạt chất được ứng dụng nhiều trong các lĩnh vực dược phẩm để kiểm soát tốc độ phóng thích thuốc, làm giàu dưỡng chất cho thực phẩm, để tránh oxy hóa hoạt chất trong mỹ phẩm. Ngoài ra, vi bọc còn giúp kiểm soát tốc độ phóng thích hoạt chất theo mong muốn. Công nghệ vi bọc được áp dụng rộng rãi trong các lĩnh vực dược phẩm, mỹ phẩm, thực phẩm, thuốc bảo vệ thực vật, phân bón. Các chất xúc tác như enzyme, vi khuẩn, nấm, xúc tác hóa học (sinh học) khi được vi bọc có thể tái sử dụng nhiều lần. Các hoạt chất như chất chống oxy hóa, hương liệu, dầu thực vật, vitamin, amino acid, chất màu, thuốc nhuộm, dễ bị hư hỏng do sự tác động của môi trường bên ngoài như ánh sáng, ẩm độ, nhiệt độ, oxygen, hoặc do phản ứng với các hóa chất khác, sẽ được tránh khỏi khi các vật liệu đó được chế tạo dưới dạng vi nang.

Các tinh dầu đã được chứng minh là có tính diệt khuẩn và có thể ứng dụng trong thuốc bảo vệ thực vật (Anitha \& ctv., 2011), mỹ phẩm (Martins \& ctv., 2014). Soliman \& ctv. (2013) đã nghiên cứu vi bọc tinh dầu quế (Cinnamon), đinh hương (Clove) và húng tây (Thyme) với hiệu suất vi bọc $90-94 \%$ và khả năng tải $22-24 \%$ bằng phương pháp ion-gel hệ Alginate-Ca dùng vòi phun khuếch tán để tạo giọt.

Tinh dầu chanh được vi bọc bằng nhiều phương pháp như trùng hợp (polymerization) sử dụng urea-formaldehyde (Park \& ctv., 2001), kết tụ phức (complex coacervation) sử dụng hai polymer là whey protein và gum arabic (Weinbreck \& ctv., 2004) và bằng sấy phun với khả năng tải tinh dầu là 10\% (Kausadikar \& ctv., 2015). Việc kiểm soát tốc độ phóng thích hoạt chất sẽ giúp chọn lựa trong ứng dụng thực tiễn (Peng \& ctv., 2010; Silva \& ctv., 2015). Tính chất của hạt Alginate-Ca2+ như bề mặt nhẵn, đồng đều cao (Fundueanu \& ctv., 1999) nên là phương pháp được ứng dụng rộng rãi để kiểm soát tốc độ phóng 
thích hoạt chất. Liên kết chéo Alginate-Chitosan bằng phương pháp ion-gel đã được nhiều nghiên cứu ứng dụng để vi bọc thuốc, protein, tế bào (Douglas, 2005). Vi bọc tinh dầu chanh bằng phương pháp ion-gel hệ Ca-Alginate chỉ mới được nghiên cứu gần đây (Trương, 2020; Truong \& ctv., 2020) nhưng chưa có báo cáo về động học phóng thích. Do vậy, trong nghiên cứu này sẽ khảo sát ảnh hưởng của nồng độ alginate lên động học phóng thích tinh dầu chanh của hệ Ca-Alginate và so sánh với hệ Ca-Alginate-Chitosan.

\section{Vật Liệu và Phương Pháp Nghiên Cứu}

\subsection{Vật liệu}

Tinh dầu chanh có nguồn gốc chiết xuất tự nhiên từ vỏ chanh tươi (chanh sần, citrus aurantifolia) và cung cấp bởi công ty Tinh dầu Thiên nhiên, Việt nam, ở địa chỉ 51/4 Phú Mỹ, Q. Bình Thạnh, TP.HCM. Sodium Alginate của Trung Quốc (Yantai Zhouji Marine Biotechnology Co., Ltd., có màu trắng, ẩm $9 \%$, protein $2,4 \%$, độ nhớt cao). Chitosan, Sodium citrate, $\mathrm{CaCl}_{2}$ và hexan của Trung Quốc.

\subsection{Phương pháp tiến hành}

Tạo hạt vi bọc Ca-Alginate: Dùng kỹ thuật đùn nhũ tương theo phương pháp dòng tia-giọt (Trương, 2020). Pha $100 \mathrm{~mL}$ Alginate trong nước cất có nồng độ cho trước đã hòa tan Tween 80 theo $1 \%$ tinh dầu. Cho tinh dầu từ từ vào bình alginate có khuấy từ $300 \mathrm{v} / \mathrm{p}$. Lượng tinh dầu cho vào được cố định ở năng suất tải lý thuyết $\left(\mathrm{LC}_{\mathrm{lt}}=\right.$ tinh dầu/(tinh dầu + Alginate $+\mathrm{CaCl}_{2}$ + Tween) là $22 \%$. Hệ nhũ tương được đồng hóa $13500 \mathrm{v} / \mathrm{p}$ bằng máy khuấy từ cơ học (Phillips HR1607) 3 phút.

Bơm nhũ tương Alginate-tinh dầu vào bình 250 $\mathrm{mL}$ chứa $\mathrm{CaCl}_{2} \quad 0,5 \%(15 \mathrm{mM})$ bằng kim tiêm có kích thước 0,26/0,51 mm (ID/OD) với lưu lượng điều khiển bằng động cơ servo sao cho đầu kim tạo ra dòng tia và hình thành giọt nhờ xung động (thiết bị của đề tài cấp Bộ B2018-NLS13 - Hình 1). Khuấy từ dịch $\mathrm{CaCl}_{2}$ liên tục, thời gian phản ứng 25 phút. Cho hạt ra vợt để trên giấy thấm 10 phút để xác định kích thước, hiệu suất vi bọc.

Độ cao kim tối ưu (Hopt) đến bề mặt dịch $\mathrm{CaCl}_{2}$ được tính toán theo các phương trình sau (Trương, 2020):

Khi $\mathrm{We}_{\mathrm{M}} / \mathrm{Oh}_{\mathrm{M}}<7,53: \mathrm{H}_{\mathrm{opt}}=257 \exp (-0,506$

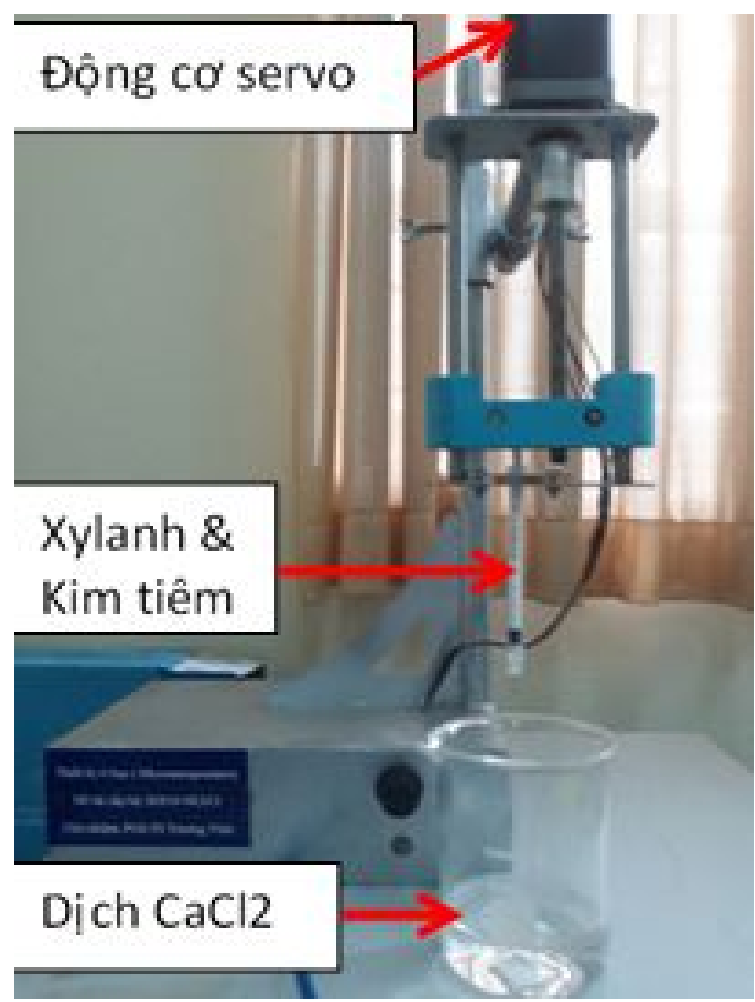

Hình 1. Thiết bị đùn dịch qua kim tiêm điều khiển bằng động cơ servo.

\section{$\left.\mathrm{We}_{\mathrm{M}} / \mathrm{Oh}_{\mathrm{M}}\right)$}

Khi $\mathrm{We}_{\mathrm{M}} / \mathrm{Oh}_{\mathrm{M}}>7,53: \quad \mathrm{H}_{\mathrm{opt}}=6,42$ $\ln \left(\mathrm{We}_{\mathrm{M}} / \mathrm{Oh}_{\mathrm{M}}\right)-7,265$

Trong đó, $\left(\mathrm{Oh}_{\mathrm{M}}\right)$ và $\left(\mathrm{We}_{\mathrm{M}}\right)$ tính theo các công thức (1) và (2).

$$
\begin{aligned}
& \mathrm{Oh}_{\mathrm{M}}=\frac{\nu \rho}{\left(\rho \mathrm{d}_{\mathrm{T}} \delta\right)^{\frac{1}{2}}} \\
& \mathrm{We}_{\mathrm{M}}=\frac{\mathrm{V}_{0}^{2} \rho \mathrm{d}_{\mathrm{T}}}{\delta}
\end{aligned}
$$

Với $\mathrm{d}_{\mathrm{T}}$ là đường kính vòi $(\mathrm{m}), \delta, \rho, \nu$ lần lượt là sức căng bề mặt, khối lượng riêng, và độ nhớt động học của dịch tham khảo từ Truong \& ctv. (2020).

Tạo hạt vi bọc Ca-Aginate-Chitosan: Ngâm hạt Ca-Alginate ở trên vào $0,08 \%$ Chitosan với thời gian phản ứng 60 phút.

Phân tích tinh dầu chanh bằng quang phổ: pha tinh dầu chanh trong hexan theo các nồng độ khác nhau. Để tìm bước sóng cho độ hấp thu cực đại, mẫu pha $0,1 \mathrm{~g}$ tinh dầu/10 mL hexan được quét ở các bước từ 290 đến $315 \mathrm{~nm}$. Thiết bị sử dụng là máy quang phổ Hewlett Packard UV-Vis. 
Sau đó dựng đường chuẩn hấp thu tinh dầu chanh ở bước sóng hấp thu cực đại.

Xác định hiệu suất vi bọc (MEY): Cân $1 \mathrm{~g}$ hạt tươi (khoảng $1 \mathrm{~g}$ ), cho vào dịch citrate $0,055 \mathrm{M}$, votex đến tan, cho $10 \mathrm{~mL}$ hexan vào và votex trong 3 phút. Ly tâm $6000 \mathrm{v} / \mathrm{p}$ trong 10 phút tách lớp, lấy hexan ở trên đo quang phổ, tính được lượng tinh dầu vi bọc $\mathrm{m}_{0}$. Hiệu suất vi bọc tính theo công thức sau, với $\mathrm{m}_{2}$ là lượng tinh dầu ban đầu trong nhũ tương Alginate- $\mathrm{CaCl}_{2}$.

$$
\operatorname{MEY}(\%)=\mathrm{m}_{0} / \mathrm{m}_{2} \times 100
$$

Hàm lượng dầu tương đối (AR): Hàm lượng dầu tương đối tính theo công thức (4) được khảo sát theo thời gian ngâm hạt vi bọc trong môi trường nghiên cứu. Trong đó $\mathrm{m}_{0}(\mathrm{t})$ là lượng tinh dầu vi bọc trong hạt tại thời điểm $t$.

$$
\mathrm{A}_{\mathrm{R}}=\mathrm{m}_{0}(\mathrm{t}) / \mathrm{m}_{2}
$$

Thí nghiệm phóng thích: Động học phóng thích được nghiên cứu trong môi trường bảo quản hạt (dịch $\mathrm{CaCl}_{2}$ ) ở nhiệt độ phòng và môi trường ứng dụng là nước ở các nhiệt độ $45^{\circ} \mathrm{C}, 60^{\circ} \mathrm{C}$ và $75^{\circ} \mathrm{C}$ để từ đó suy rộng kết quả cho các nhiệt độ thấp hơn và cao hơn, dự kiến ứng dụng trong các điều kiện chế biến (nấu, hấp, sấy, xử lý nhiệt) và bảo quản sản phẩm. Thí nghiệm bảo quản hạt vi bọc ở nhiệt độ phòng tiến hành trong thời gian dài đến 90 ngày trên một số dịch có nồng độ $\mathrm{CaCl}_{2}$ khác nhau. Thí nghiệm phóng thích ở nhiệt độ 45 - $75^{\circ} \mathrm{C}$ thực hiện trong 1 tuần dể rút ngắn thời gian khảo sát nhằm có kết quả nhanh. Có các thí nghiệm sau đây.

Ảnh hưởng của nồng độ $\mathrm{CaCl}_{2}$ lên sự phóng thích tinh dầu của hệ Ca-Alginate: Cố định nồng độ alginate $1,5 \%$, thay dổi nồng độ $\mathrm{CaCl}_{2}$ từ $0 \%$ đến $1 \%$, nhiệt độ môi trường.

Ảnh hưởng của nồng độ alginate và nhiệt độ nước lên sự phóng thích tinh dầu của hệ $\mathrm{Ca}$ Alginate: thay đổi nồng độ alginate $2 \%-3 \%$. Nhiệt độ nước $45^{\circ} \mathrm{C}, 60^{\circ} \mathrm{C}$ và $75^{\circ} \mathrm{C}$.

So sánh hệ Ca-Alginate và Ca-AlginateChitosan: Cố định nồng độ alginate 2,5\%, dịch $\mathrm{CaCl}_{2} 1 \%$, nhiệt độ môi trường.

\subsection{Phân tích thống kê}

Phân tích hồi qui bằng phần mềm Excel, phân tích ANOVA bằng phần mềm Statgraphics centurion v15.1.

\section{Kết Quả và Thảo Luận}

Chọn bước sóng và dựng đường chuẩn: Độ hấp thu cực đại tại $295 \mathrm{~nm}$ và đường chuẩn khảo sát trong Truong \& ctv. (2020) được chọn để phân tích tinh dầu trong mẫu hạt vi bọc.

Ảnh hưởng của nồng độ $\mathrm{CaCl}_{2}$ lên động học phóng thích tinh dầu chanh: Hình 2 cho thấy ảnh hưởng của nồng độ $\mathrm{CaCl}_{2}$ lên động học phóng thích của tinh dầu chanh ở nhiệt độ thường. Nồng độ $\mathrm{CaCl}_{2}$ càng cao thì tinh dầu phóng thích càng chậm. Trong thí nghiệm này, ở $\mathrm{CaCl}_{2} 0 \%$ tức môi trường nước có ý nghĩa ứng dụng trong các sản phẩm dạng lỏng. Ở các môi trường $\mathrm{CaCl}_{2}$ cao hơn cho thấy tiềm năng bảo quản hạt vi bọc sau khi sản xuất. Tinh dầu còn trong hạt đến $68 \%$ sau 60 ngày bảo quản ở $\mathrm{CaCl}_{2} \quad 0,75 \%$. Tương tự, tinh dầu còn $57 \%$ sau 90 ngày bảo quản ở $\mathrm{CaCl}_{2} 1 \%$. Trong lúc đó, ở trong môi trường nước thì sau 4 ngày tinh dầu còn $66 \%$.

Áp dụng mô hình phóng thích tinh dầu bậc 1 như phương trình (5), trong đó $\mathrm{A}$ là hàm lượng tinh dầu ở trong hạt tại thời điểm $\mathrm{t}$, và $\mathrm{k}$ là động học phóng thích, từ đó suy ra hàm lượng tinh dầu $\mathrm{A}$ tại thời điểm $\mathrm{t}$ theo hàm lượng tinh dầu ban đầu $\left(\mathrm{A}_{\mathrm{o}}\right)$ trong hạt vi bọc theo $(6)$, hoặc hàm lượng dầu tương đối $\mathrm{AR}=\mathrm{A} / \mathrm{A}_{\mathrm{o}}(7)$, với $\mathrm{k}$ cho trên Bảng 1.

$$
\begin{gathered}
\mathrm{d}(\mathrm{A}) / \mathrm{dt}=-\mathrm{kA} \\
\ln (\mathrm{A})=-\mathrm{kt}+\ln \left(\mathrm{A}_{\mathrm{O}}\right) \\
\ln (\mathrm{AR})=-\mathrm{kt}
\end{gathered}
$$

Sự giảm tốc độ phóng thích thể hiện bằng sự giảm hằng số động học $\mathrm{k}$ khi tăng nồng độ $\mathrm{CaCl}_{2}$ như ở Bảng 1. Mặc dầu sự tương quan chưa chặt chẽ, nhưng độ dốc tương đối có xu hướng giảm liên tục khi tăng nồng độ $\mathrm{CaCl}_{2}$.

Bảng 1. Hằng số động học $\mathrm{k}$ ở các nồng độ $\mathrm{CaCl}_{2}$ khác nhau

\begin{tabular}{cccccc}
\hline $\mathrm{CaCl}_{2}$ & $0 \%$ & $0,25 \%$ & $0,5 \%$ & $0,75 \%$ & $1 \%$ \\
\hline $\mathrm{k}$ & 0,091 & 0,035 & 0,008 & 0,007 & 0,006 \\
\hline
\end{tabular}

Ảnh hưởng nồng độ alginate lên động học phóng thích tinh dầu chanh trong môi trường nước ở nhiệt độ $45^{\circ} \mathrm{C}-75^{\circ} \mathrm{C}$ : Hiệu suất vi bọc tinh dầu chanh tăng dần $(79-86 \%)$ khi nồng độ 


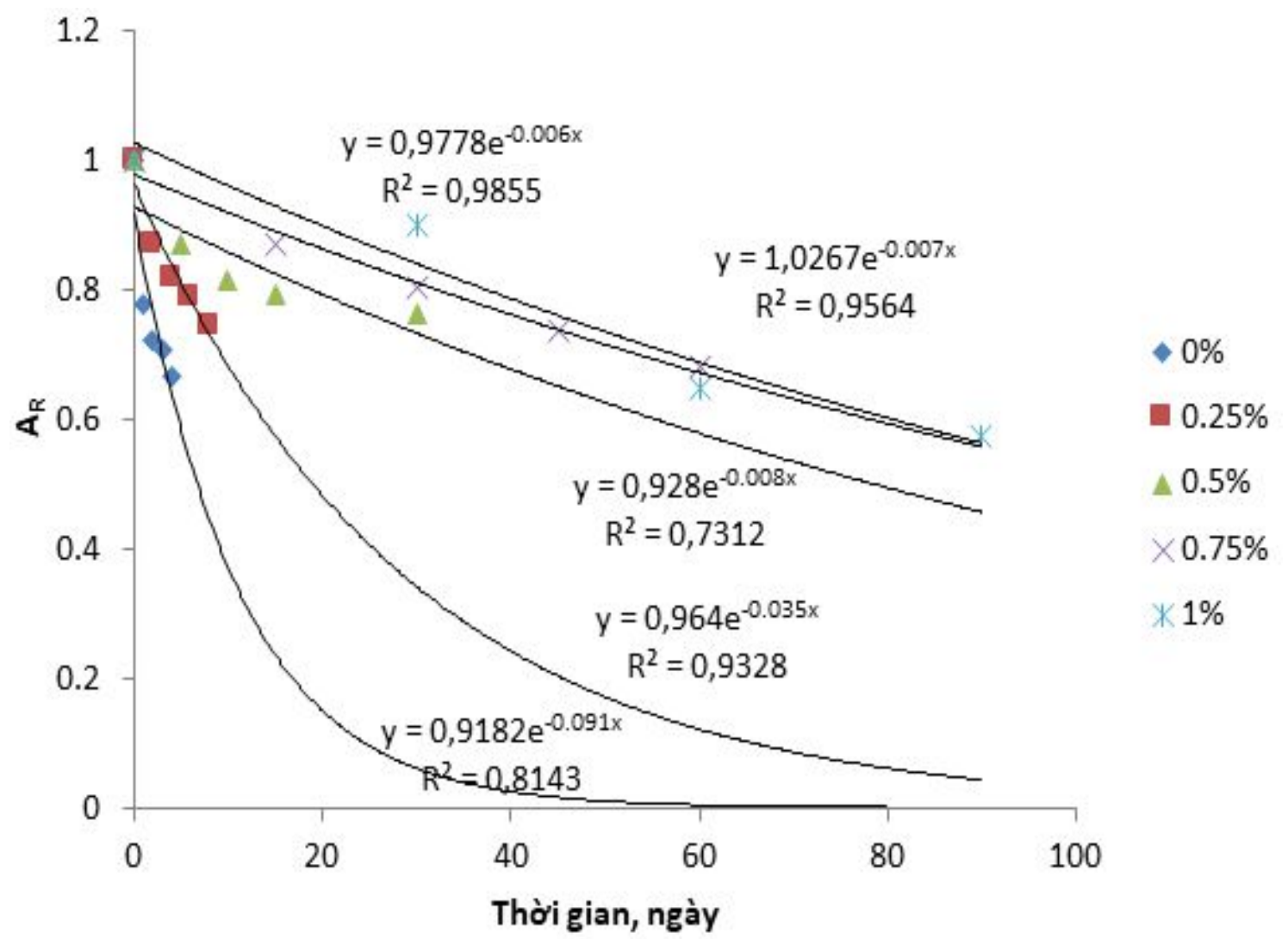

Hình 2. Ảnh hưởng của nồng độ $\mathrm{CaCl}_{2}$ lên động học phóng thích tinh dầu chanh.

Bảng 2. Sự phóng thích tinh dầu tương đối ở các nồng độ alginate khác nhau trong môi trường nhiệt độ nước khác nhau

\begin{tabular}{|c|c|c|c|c|c|c|c|c|c|}
\hline \multirow{2}{*}{ Ngày } & \multicolumn{3}{|c|}{$45^{\circ} \mathrm{C}$} & \multicolumn{3}{|c|}{$60^{\circ} \mathrm{C}$} & \multicolumn{3}{|c|}{$75^{\circ} \mathrm{C}$} \\
\hline & $2 \%$ & $2,50 \%$ & $3 \%$ & $2 \%$ & $2,50 \%$ & $3 \%$ & $2 \%$ & $2,50 \%$ & $3 \%$ \\
\hline$\overline{0}$ & 1 & 1 & $\overline{1}$ & 1 & $\overline{1}$ & 1 & 1 & 1 & 1 \\
\hline 1 & 0,95 & 0,96 & 0,98 & 0,93 & 0,96 & 0,97 & 0,92 & 0,96 & 0,96 \\
\hline 2 & & & & & & & 0,84 & 0,92 & 0,91 \\
\hline 3 & $\begin{array}{lll}0,92 & 0,93\end{array}$ & 0,96 & 0,89 & 0,93 & 0,93 & & & & \\
\hline 4 & & & 0,86 & 0,91 & 0,91 & & & & \\
\hline 7 & 0,81 & 0,86 & 0,89 & & & & & & \\
\hline
\end{tabular}

alginate tăng dần từ $2 \%-3 \%$. Ở $45^{\circ} \mathrm{C}$, tinh dầu phóng thích $20 \%, 15 \%$ và $12 \%$ cho các nồng độ 2 ; 2,5 và $3 \%$ sau 7 ngày bảo quản trong môi trường nước ở $45^{\circ} \mathrm{C}$ (Hình 3). Sự phóng thích tương đối của tinh dầu so với ban đầu cho trên Bảng 2 . Kết quả cho thấy sau 1 ngày, nồng độ $3 \%$ alginate còn giữ 96 - 98\% trong khoảng nhiệt độ $45^{\circ}-75^{\circ} \mathrm{C}$.

Tương tự như vậy là $96 \%$ và $92-95 \%$ cho alginate $2,5 \%$ và $2 \%$. Điều này chứng tỏ rằng, khi sử dụng hạt vi bọc trong các sản phẩm có quá trình thanh trùng ở khoảng nhiệt độ $45^{\circ}-75^{\circ} \mathrm{C}$ thì hầu như tinh dầu không mất đi. Nồng độ alginate càng cao thì tốc độ phóng thích càng giảm.

Kết quả hồi qui ở các Hình 4,5 và 6 cho thấy đa số tương quan khá chặt với hệ số $\mathrm{R}^{2}$ trên 0,98 ngoại trừ trường hợp ở $60^{\circ} \mathrm{C}$ có lẽ do sự biến động của số liệu lúc phân tích mẫu.

Bảng 3 và 4 cho thấy nhiệt độ càng cao thì hệ số $\mathrm{k}$ càng lớn tức phóng thích càng nhanh. Điều này cũng tương tự kết quả của Peng \& ctv. (2010) ở nhiệt độ khác nhau. Ở nhiệt độ $45^{\circ} \mathrm{C}$ cần 23 - 40 


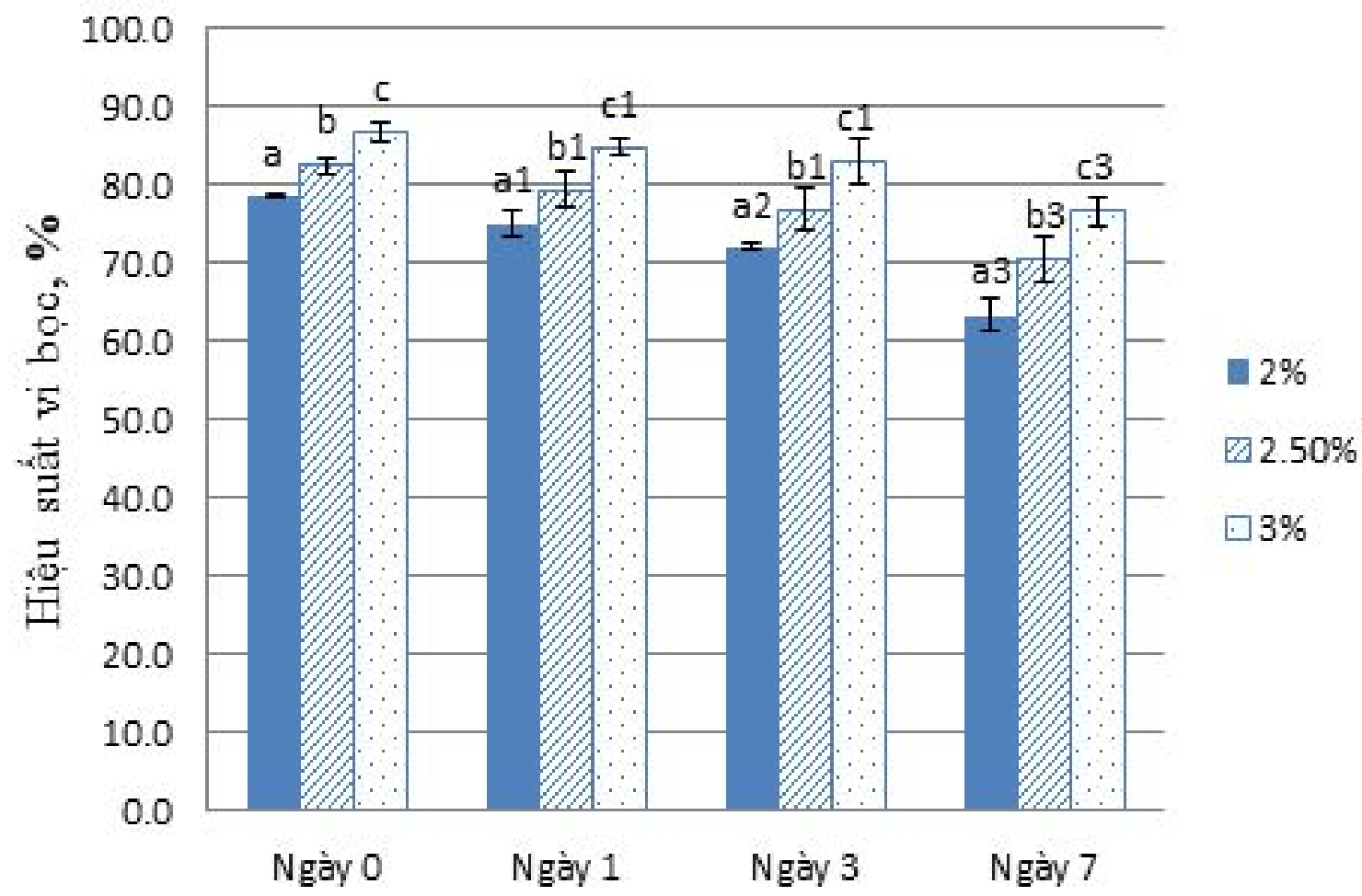

Hình 3. Sự phóng thích tinh dầu sau 7 ngày trong nước ở nhiệt độ $45^{\circ} \mathrm{C}$ thể hiện qua độ giảm hiệu suất vi bọc. Các kí tự khác nhau thể hiện sự khác biệt thống kê $(P<0,05)$.

ngày mới giảm 50\% nồng độ tinh dầu trong hạt ứng với alginate 2 - 3\%. Động học phóng thích của alginate $2,5 \%$ và $3 \%$ hầu như không khác nhau ở nhiệt độ $60^{\circ}-75^{\circ} \mathrm{C}$.

Bảng 3. Tổng kết động học phóng thích $\mathrm{k}$ của tinh dầu chanh trong hạt vi bọc

\begin{tabular}{cccc}
\hline \multirow{2}{*}{ Nhiệt độ nước, ${ }^{\circ} \mathrm{C}$} & \multicolumn{3}{c}{ Nồng độ alginate, $\%$} \\
\cline { 2 - 4 } & 2,0 & 2,5 & 3,0 \\
\hline 45 & 0,0298 & 0,0213 & 0,0172 \\
60 & 0,0351 & 0,0220 & 0,0223 \\
75 & 0,0855 & 0,0425 & 0,0481 \\
\hline
\end{tabular}

Bảng 4. Thời gian (ngày) giảm $50 \%$ tinh dầu ( $\left.\mathrm{t}_{50}\right)$ của hạt vi bọc khi bảo quản trong nước tính từ các mô hình hồi qui

\begin{tabular}{cccc}
\hline \multirow{2}{*}{ Nhiệt độ nước, ${ }^{\circ} \mathrm{C}$} & \multicolumn{3}{c}{ Nồng độ alginate, $\%$} \\
\cline { 2 - 4 } & 2,0 & 2,5 & 3,0 \\
\hline 45 & 23,3 & 32,5 & 40,3 \\
60 & 19,8 & 31,6 & 31,1 \\
75 & 8,1 & 16,3 & 14,4 \\
\hline
\end{tabular}

Theo Trương (2020), khi sản xuất hạt vi bọc theo phương pháp dòng tia-giọt, độ cầu ở 3\% al- ginate rất khó đạt $92 \%$, trong lúc ở 2,5\% alginate có thể đạt $95 \%$. Như vậy có thể chọn alginate 2 - 2,5\% là nồng độ tối ưu khi muốn bảo quản lâu dài và phóng thích chậm, hoặc trong điều kiện chế biến nhiệt độ cao.

So sánh hệ Ca-Alginate và Ca-AlginateChitosan: Định hướng trong sản xuất công nghiệp, hạt vi bọc sẽ được sản xuất hàng loạt và bảo quản trong môi trường $\mathrm{CaCl}_{2}$ ở nhiệt độ phòng $\left(25-30^{\circ} \mathrm{C}\right)$ trước khi được sử dụng trong các sản phẩm cụ thể. Khi bảo quản trong môi trường $\mathrm{CaCl}_{2} 1 \%$, sự phóng thích tinh dầu sẽ chậm hơn (Hình 7).

Với hệ Ca-Alginate, từ ngày 0 dến ngày 3 hàm lượng tinh dầu phóng thích ra nhiều (khoảng $6 \%$ so với ban đầu) do lớp vỏ vi bọc chưa dày vì thời gian phản ứng giữa Aglinate và $\mathrm{CaCl}_{2}$ chỉ khởi đầu 25 phút và kéo dài 3 ngày. Bắt đầu từ ngày 3 đến ngày 45 thì lớp vỏ vi bọc đủ dày để ngăn cản sự phóng thích tinh dầu vì vậy hàm lượng tinh dầu giảm nhẹ không đáng kể (rõ rệt nhất là từ ngày 30 đến ngày 45 hàm lượng tinh dầu giảm khoảng 1\%). Sau 45 ngày, hàm lượng tinh dầu chỉ giảm $10 \%$ so với ban đầu. Với hệ Ca-alginate- 


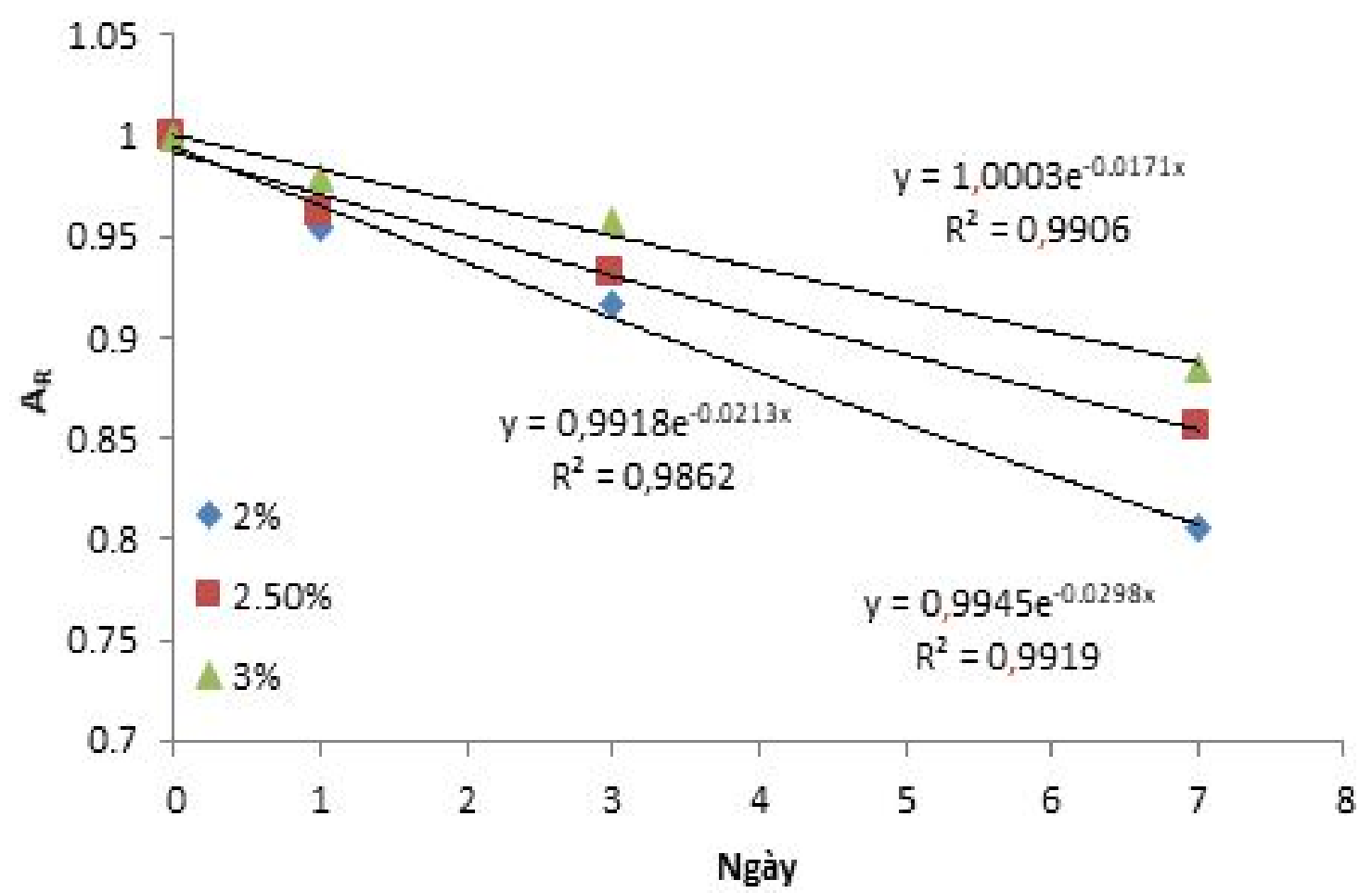

Hình 4. Ảnh hưởng của nồng độ alginate lên động học phóng thích tinh dầu ở $45^{\circ} \mathrm{C}$.

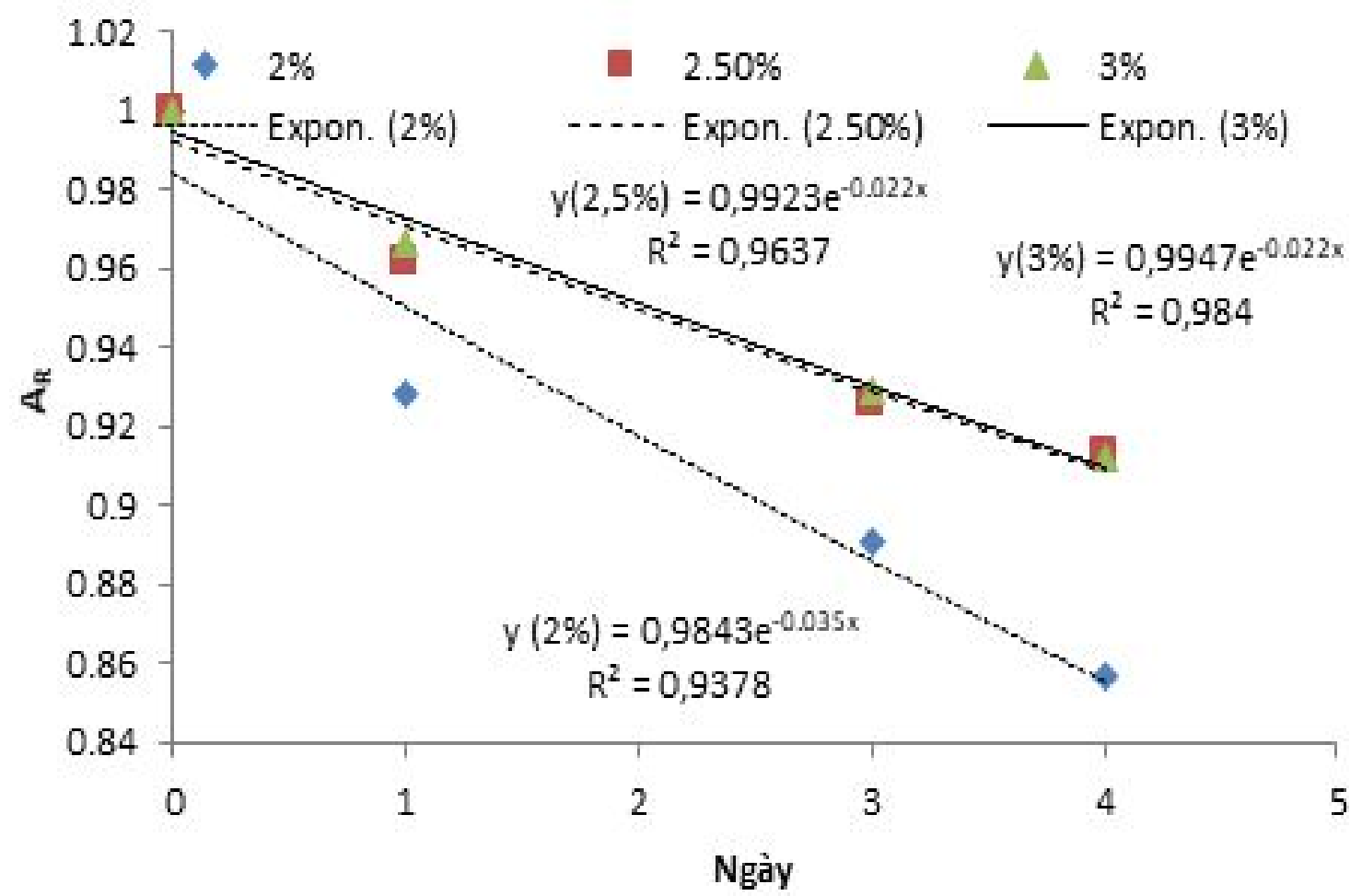

Hình 5. Ảnh hưởng của nồng độ alginate lên động học phóng thích tinh dầu ở $60^{\circ} \mathrm{C}$. 
$\begin{array}{lll}2 \% & 2.50 \% & \mathbf{4} 3 \%\end{array}$

Expon. (2\%) — Expon. (2.50\%) ---- Expon. (3\%)

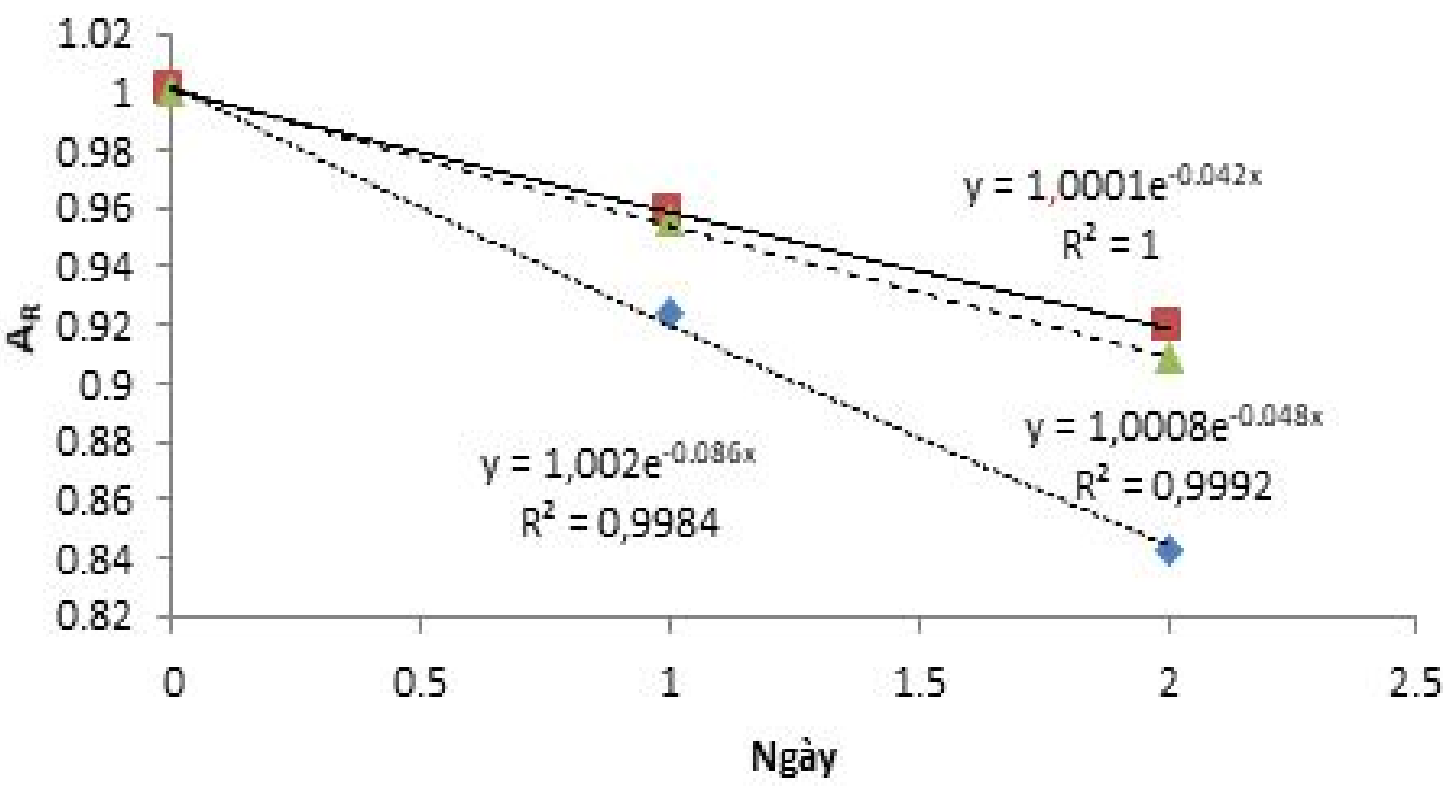

Hình 6. Ảnh hưởng của nồng độ alginate lên động học phóng thích tinh dầu ở $75^{\circ} \mathrm{C}$.

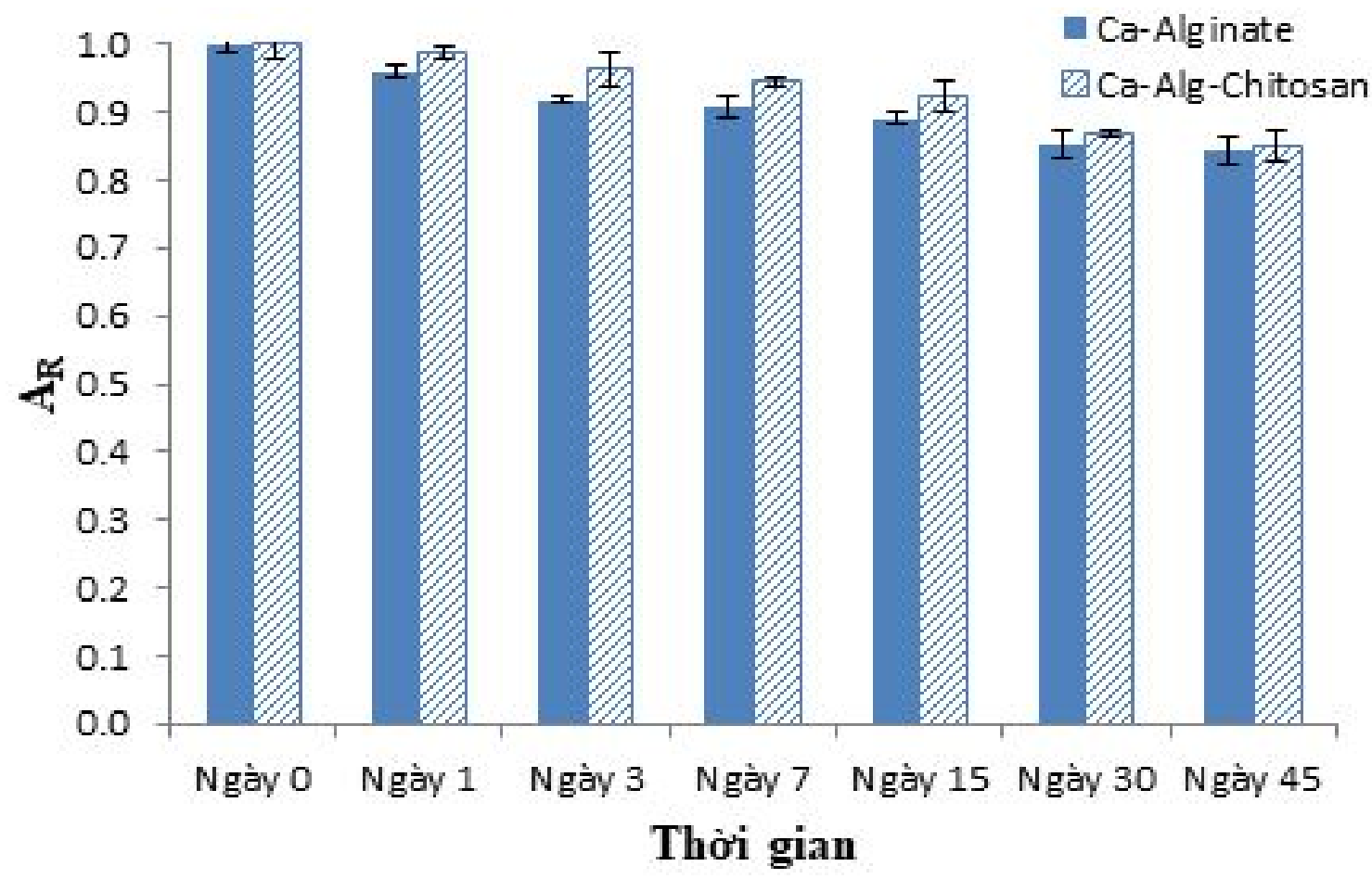

Hình 7. So sánh độ phóng thích tinh dầu chanh của hạt vi bọc Ca-alginate và Ca-alginate-Chitosan của alginate $2,5 \%$ ở trong môi trường $\mathrm{CaCl}_{2} 1 \%$. 
Chitosan thì để giảm $6 \%$ cần tới 15 ngày nói lên tốc độ phóng thích chậm hơn hệ Ca-alginate do lớp Chitosan. Hai hệ vi bọc $\mathrm{Ca}$-alginate và $\mathrm{Ca}$ alginate-Chitosan có khác nhau về hiệu suất vi bọc và độ phóng thích ở giai đoạn 15 ngày đầu nhưng không khác biệt sau thời gian dài. Điều này chứng tỏ nếu bảo quản trong môi trường $\mathrm{CaCl}_{2}$ $1 \%$ thì liên kết Ca-Alginate chiếm ưu thế nên ảnh hưởng của Chitosan không đáng kể. Tuy nhiên, thí nghiệm chỉ thử ở $0,08 \%$ Chitosan với thời gian phản ứng 60 phút nên không thấy ảnh hưởng của Chitosan ở thời gian bảo quản trên 45 ngày. Cần thí nghiệm thêm với các nồng độ và thời gian khác.

\section{Kết Luận}

Tinh dầu chanh vi bọc bằng phương pháp iongel tạo hạt bằng kỹ thuật dòng tia-giọt có độ phóng thích trong nước tùy thuộc nồng độ alginate và nhiệt độ nước. Alginate được sử dụng làm polymer có ion âm để liên kết với ion dương của calcium. Nồng độ $\mathrm{CaCl}_{2}$ có ảnh hưởng đến sự phóng thích tinh dầu chanh. Ở nhiệt độ $45^{\circ} \mathrm{C}$, sự phóng thích tinh dầu trong nước phụ thuộc rõ ràng vào nồng độ Alginate từ 2 đến $3 \%$. Tuy nhiên, không có sự khác biệt của sự phóng thích tinh dầu giữa 2 nồng độ alginate $2,5 \%$ và $3 \%$ khi nhiệt độ trên $60^{\circ} \mathrm{C}$. Chitosan có điện tích dương cũng tham gia liên kết chéo với alginate làm giảm độ phóng thích tinh dầu so với chỉ có liên kết Ca-alginate. Khi bảo quản trong môi trường dịch $\mathrm{CaCl}_{2}$, sự liên kết Ca-Alginate tiếp tục xảy ra và chiếm ưu thế so với liên kết Alginate-Chitosan.

\section{Tài Liệu Tham Khảo (References)}

Anitha, K., Ramachandran, T., Rajendran, R., \& Mahalakshmi, M. (2011). Microencapsulation of lemon grass oil for mosquito repellent finishes in polyester textiles. Elixir International Journal 40, 5196-5200.

Douglas, K. L., \& Tabrizian, M. (2005). Effect of experimental parameters on the formation of alginate-chitosan nanoparticles and evaluation of their potential application as DNA carrier. Journal of Biomaterials Science, Polymer Edition 16(1), 43-56.
Fundueanu, G., Nastruzzi, C., Carpov, A., Desbrieres, J., \& Rinaudo, M. (1999). Physico-chemical characterization of Ca-alginate microparticles produced with different methods. Biomaterials 20(15), 1427-35.

Kausadikar, S., Ashish, D. G., \& Jyotsna, W. (2015). Microencapsulation of lemon oil by spray drying and its application in flavour tea. Advances in Applied Science Research 6(4), 69-78.

Martins, I. M., Maria, F. B., Manuel, C., \& Alírio, E. R. (2014). Microencapsulation of essential oils with biodegradable polymeric carriers for cosmetic applications. Chemical Engineering Journal 245, 191-200.

Park, S. J., Shin, Y. S., \& Lee, J. R. (2001). Preparation and characterization of microcapsules containing lemon oil. Journal of Colloid and Interface Science 241(2), 502-508.

Peng, H., Xiong, H., Li, J., Xie, M., Liu,Y., Bai,C., \& Chen, L. (2010). Vanillin cross-linked chitosan microspheres for controlled release of resveratrol. Food Chemistry 121(1), 23-28.

Silva, E. K., Giovani, L. Z., Angela, M., \& Meireles, A. (2015). Ultrasound-assisted encapsulation of annatto seed oil: Retention and release of a bioactive compound with functional activities. Food Research International 78, 159-168.

Soliman, E. A., El-Moghazy, A. Y., Mohy El-Din, M. S., \& Massoud, A. M. (2013). Microencapsulation of essential oils within alginate: Formulation and in vitro evaluation of antifungal activity. Journal of Encapsulation and Adsorption Sciences 3(1), 48-55.

Truong, V. (2020). Effectiveness of liquid jet breakup and jet cutting systems used in microencapsulation processes of cosmetics, pharmaceuticals and foods (Report of Project B2018-NLS13 funded by the Ministry of Education and Training of Vietnam). Nong Lam University, Ho Chi Minh City, Vietnam.

Truong, V., Nguyen, P. T., Ta, P. N. M., Nguyen, P. T., \& Pham, N. T. C. (2020). Effects of type and concentration of alginate on microencapsulation characteristics of lime essential oil (Citrus aurantifolia) produced by extrusion-dripping methods. The Journal of Agriculture and Development 19(1), 65-76.

Weinbreck, F., Minor, M., \& De Kruif, C. G. (2004). Microencapsulation of oils using whey protein/gum arabic coacervates. Journal of Microencapsulation 21(6), 667-679. 